sequently funded) had appeared in a review article entitled "Tumour Dormancy" by A. E. K. Alsabti (Journal of Cancer 1979) which had also appeared in the Czech journal Neoplasma $(26,351 ; 1979)$.

Professor Wheelock said earlier this week that he was hoping to persuade each of the journals to publish a correction. He said that Dr Alsabti had worked in his laboratory for a period of five months but that he had asked him to leave after a disagreement about the authenticity of some experimental data.

Another case in which Dr Alsabti's authorship is questioned is his article "Diagnosis of serum lipids in hepatoma", published in Oncology (36, 11 1979). This so resembles an article by Yoshida et al. in the Japanese Journal of Clinical Oncology $(7,15 ; 1977)$ that the editor of the journal has written to Oncology saying "I was shocked by the appearance of Dr Alsabti's article which seems a copy of that by Yoshida et al. . . .". A copy of this letter has been seen by Dr J. Moglivit of the Anderson Medical Center in Houston, Texas, who was for seven months the immediate supervisor of Dr Alsabti during his spell as a volunteer (unpaid) technician there at the end of 1978 .

Dr A. Clarke, president of the Medical Center, said on the telephone earlier this week that Alsabti had come to work in Texas on the recommendation of a Jordanian friend of the hospital but that in the end he was dismissed as a volunteer because of reports reaching the hospital of his exaggerated claims about the work that he had been doing.

One of the referees to whom the paper by Wierda et al. was sent by the European Journal of Cancer was Dr J. A. Gottlieb of the Anderson Center at Houston. Dr Alsabti was at the center towards the end of 1978. Dr Gottlieb had died some time before. Research and Clinical Oncology, 95, 209;

Index Medicus records that Dr Alsabti published 13 articles in the scientific literature during 1979 and ten in the first five months of this year.

\section{Drug regulations Signs change}

\section{Washington}

The drug industry has won a measure of support from the General Accounting Office in its complaint that the bureaucracy takes too long to license new products. In a report published last week (6 May), and based largely on comparisons with licensing practice in other industrialised countries, the GAO says that American practice is "lengthy" and that this circumstance "delays the benefits important drugs can provide to the public'.

The fact that a new drug application takes on the average 20 months between the submission of test data and the receipt of licensing approval has been a hot potato in Washington for almost ten years. Without making any explicit judgement on the time needed to ensure that the scientific data is adequately reviewed, the GAO report does echo what many pharmaceutical companies have been saying for the past decade.

Excessive regulation, they claim, has not only escalated the costs of bringing a new drug to the market - now estimated at an average of $\$ 62$ million - but has led to a growing proportion of their research being conducted outside the United States in countries with easier licensing regulations.

The Food and Drug Administration accepts that its licensing process is lengthy and has taken steps to accelerate the scientific review process. Two years ago, for example, it committed itself to reducing the time taken to license important new drugs by 25 per cent a year over three

\section{Two figures - Wierda et al. bottom left}

54 $A L S A B T I$ et al.

Yol. 32
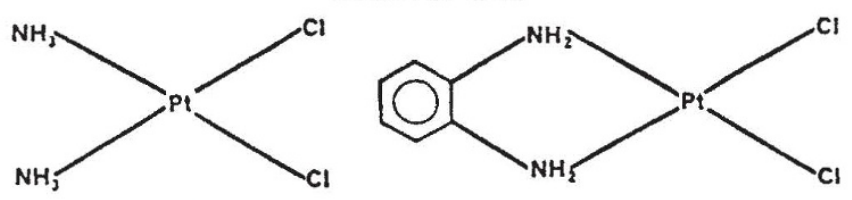

DDP

DBP

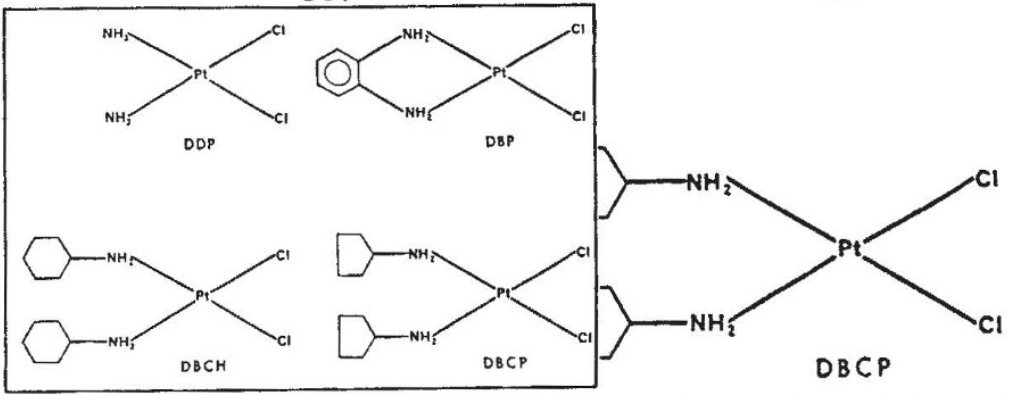

Fig. 1. Chemical structures of cis-dichlorodiammine platium (DDP), dichloro 1,2 benzenediamine $\mathrm{N}, \mathrm{N}^{\prime}$ platinum (DBP), cis-dichlorobis(cyclohexylamine) platinum (DBCH), and cisdichlorobis(cyclopentylamine) platinum (DBCP). successive years, and claims to be on target. But the charges continue that the FDA is not doing enough. And last week congressmen keen further to speed the process quoted the GAO's conclusion that, based on a comparison of the time taken to license fourteen important drugs in six countries, the United States was slower than most in all but one case. According to the GAO, whereas it took on average five months to have a new drug approved in Great Britain and sixteen in Canada, the average time in the United States was 23 months, exceeded only by Sweden's 28 months. FDA counters with its own statistics. Analysis shows, it says, that "the few important drugs that genuinely advance medical care ... tend to be approved today at reasonably similar times (generally within a few months) in most developed countries",

In response to the charge that its review procedures are too stringent, the agency replies that "of all new molecular entities [drugs whose active ingredient has not previously been marketed in the US] introduced into world medicine in the past decade, no country has approved more than 50 per cent of the total"'.

Behind the numbers game lie deeper arguments that illustrate how the time taken to approve new drugs is determined as much by the way that the United States has chosen to regulate the drug industry with a heavy emphasis on administrative record and documented evaluation - as on the adequacy of particular regulations. Pointing to European countries, for example, where independent advisory committees can provide a buffer between a regulatory agency and the industry, the GAO suggests similar expert committees might be used more to review and approve new drugs in the United States.

The FDA disagrees. It says that the open nature of regulatory decision-making in the United States, the right of individuals to sue the government over regulatory actions and the powerful role of congressional oversight each make it difficult to go beyond the thirteen advisory committees now in place.

Another issue is that of post-marketing surveillance. The GAO report points out that in countries such as Great Britain with a national health care system, close contact between doctors and the health services encourages feedback and limits the potential dangers of premature licensing. The FDA, however, has very limited authority to take action on a drug once it has been released, and thus tends to be more cautious before giving licensing approval. There are also suggestions that physicians and hospitals may be dissuaded by the fear of increased medical liability from reporting their experiences.

Tighter provisions for post-marketing surveillance, including in particular the requirement that manufacturers should oblige doctors to notify them of any adverse side-effects, are a central feature of 
two drug regulatory reform bills currently under joint consideration in the House of Representatives.

Both bills are intended to speed up the licensing process, one introduced by the Administration, the other drawn up by Senator Edward Kennedy and passed last autumn by the Senate. For example, an arbitration process would be set up for scientific disagreements between the FDA and potential licensees.

Both bills meet the concern of the FDA that, in particular, it should be given greater flexibility in licensing. They propose, for example, that the review procedure should be speeded up for exceptionally important new drugs and that licences should be issued restricting the use of a drug to specified circumstances where general release might be undesirable.

The pharmaceutical companies are, in general, keen on such revisions. Consumer groups are less happy. "Greater licensing flexibility for so-called breakthrough drugs could provide the camel's head under the tent as far as weakening the general protection provided by the drug laws", says Ben Gordon of the Nader-affiliated Health Resources Group.

But the most important factor may prove to be a recent arrival, namely growing congressional enthusiasm for moves to stimulate industrial innovation in the face of declining productivity and increasing foreign competition, Japanese in particular.

The wish to meet this threat may prove the most potent weapon in the regulation reformers' armoury.

David Dickson

\section{Comecon}

\section{Links with West}

East-West scientific exchange, except at the Academy/Royal Society level, tends to become associated with other, not strictly academic, matters, as no fewer than three events in London during the past fortnight have demonstrated.

The first, a working visit of the Polish Minister of Metallurgy, Franciszek Kaim, resulted in the signing of two contracts between his ministry, on the one hand, and the British Steel Corporation and the British Metallurgical Producers Association respectively on the other. Although these agreements deal mainly with highly specific themes, such as new technologies for producing coke from noncoking coal, and the perennial theme of energy and raw materials saving, Mr Kaim indicated that on the Polish side at least, a great number of institutes and "other organizations which specialize in scientific research" would be involved in working out "ways and means".

At a later stage, Kaim said, there might be joint research between UK and Polish scientists, both in developing new types of steel and in basic metallurgical research. $\overline{0028-0836 / 80 / 240431-02501.00}$
Environment, too, he stressed, was a subject where there could be "very effective joint cooperation". (This is a sensitive issue for his ministry - only a few days before his visit, workers at the giant Lenin Steel Mills at Nowa Hut had passed a resolution that existing environmental protection measures there were insufficient.)

This was the third such UK-Polish agreement to be signed - one on mining was signed some three years ago, and one on electricity in February 1980. It comes within the framework of the Joint Commission on Trade and Technology (a linkage that arises, at least in part, from the way in which the former UK Ministry of Technology was dismantled). So did the GDR Engineering Week in Britain (2-5 June 1980).

The East Germans, however, are far less happy about the linking of technological exchange with trade, and are constantly pressing for separate international agreements to cover both. Yet for the purpose of the "Week", Dr Gerhard Beil, Secretary of State in the Ministry of Foreign Trade of the GDR, was prepared to waive these demands - the objective, he said, was "to deepen economic, scientific and technological relations".

The mighty instrument firm of VEB Zeiss-Jena makes no distinction of this kind. After a comprehensive lecture on its latest measuring instruments for the metallurgical industry, the Zeiss delegates made it quite clear that there is no distinction between the scientific and industrial instruments produced by Zeiss in the minds of the 4,000 scientists on the staff.

The third event in the past two weeks had, by contrast, little or no commercial application. Bulgaria is at present preparing for next year's celebrations of 1300 years of statehood, and, in the past few years, has been doing some quite remarkable work in molecular biology. As part of the celebrations, therefore, last week, at the Bulgarian Embassy in London, Sir John Kendrew, in recognition of his services to molecular biology, was invested with the Order of the Madara Horseman and, at the same time, made an honorary foreign member of the Bulgarian Academy of Sciences.

Vera Rich

\section{Biotechnology}

\section{Canada stirs}

Anxious not to be left behind, the Canadian government is setting up an independent working group to tell whether and how it should promote the growth of biotechnology.

The nine members of the working group are to report back within a year to the Minister of State for Science and Technology, Mr John Roberts, who announced the government's decision on Tuesday at a meeting of the Chemical Institute of

\section{Canada.}

The chairman of the group is Dr Maurice Brossard, director of research at the Institut Armand Frappier in Laval, Quebec. Of the remaining eight members, three are from universities and five from industry; others, including government scientists, will be involved as consultants. Although one objective of the working group is to assess the potential of Canada to compete directly with other countries in fields such as the biological production of industrial chemicals and health care products, it is hoped that the group will pay special attention to Canada's characteristic resources and needs - in fields such as energy, mining, food, agriculture and forestry.

Accompanying Mr Roberts's announcement was the publication of a background paper prepared by Dr Louis Slotin, secretary of the committee, listing current Canadian research efforts in biotechnology, broadly defined to include genetic and cellular manipulation, enzyme technology and fermentation techniques.

The report reveals a moderate amount of effort, with total support amounting to about several million dollars a year. But it tends to be thinly spread. The 100 university research workers listed, for example, are distributed among 22 universities; and of the 33 companies indicating an interest in biotechnology research, only ten have more than one or two research workers involved.

To a certain extent Canada makes up in quality what it lacks in quantity. Scientists in the National Research Council's Division of Biological Sciences, for example, are acknowledged to be among the world's leaders in the study of the insulin gene; and several prominent Canadian biologists are already employed as advisers and consultants to US-based biotechnology companies.

The most serious difficulty ahead is a familiar one for Canada - how can an industrial sector largely dominated by foreign-based companies - often with their main research facilities in the United States or elsewhere - be encouraged to support research in Canada and to use what is already being done? There is also a gulf between university research and its potential applications. No Canadian university has a department of applied microbiology, while microbiological research is carried out almost exclusively in medical schools.

A broader issue for the working party will be that of government policy on innovation and whether it should provide direct support for broad-based industrial initiatives - as recommended in Britain's Spinks Report - or instead to follow US strategy with tax incentives and the like.

The inclination of both scientists and industrialists is towards less rather than more government involvement but with a different industrial structure and a smaller supply of individuals prepared to make 